\title{
Violência Doméstica e Crianças em Risco: Estudo Empírico com Autos da Polícia Portuguesa
}

\author{
Ana Isabel Sani1,* \& Cristiana Carvalho ${ }^{1}$ \\ ${ }^{1}$ Universidade Fernando Pessoa (UFP), Lisboa, Portugal
}

\begin{abstract}
RESUMO - Apresenta-se um estudo exploratório misto baseado na análise de autos de notícia e denúncia por crime de violência doméstica, reportados em 2010 à Polícia de Segurança Pública (Porto, Portugal). O objetivo do estudo foi examinar a presença de crianças, direta ou indiretamente envolvidas nessas situações. A análise estatística de 167 autos revelou que $45 \%$ referiam-se a famílias com filhos, admitindo-se que, em $29 \%$, a violência era presenciada por crianças. A análise de conteúdo de 141 autos revelou existir também violência física e psicológica incidindo diretamente sobre as crianças e jovens, incluindo instrumentalização dos filhos. Conclui-se pela evidência do fenômeno de exposição de crianças à violência doméstica e pela necessidade de os agentes policiais reforçarem a sua formação para o atendimento a crianças em situação de risco.
\end{abstract}

PALAVRAS-CHAVE: violência doméstica, criança em risco, autos da polícia

\section{Domestic Violence and Children at Risk: Empirical Study of Portuguese Police Records}

\begin{abstract}
We present a mixed exploratory study based on the analysis of news reports and denunciations for domestic violence, reported in 2010 to the Public Security Police (Porto, Portugal). The purpose of this study was to examine the presence of children, directly or indirectly involved in these situations. Statistical analysis of 167 reports revealed that $45 \%$ were from families with children, and in $29 \%$ the violence was witnessed by children. Content analysis of 141 reports also revealed physical and psychological violence directly on children and young people, including their manipulation. We concluded that there is evidence of exposure of children to domestic violence and there is a need of police officers to reinforce their specialized training on children at risk.
\end{abstract}

KEYWORDS: domestic violence, children at risk, reports of police

A violência doméstica é um conceito genérico que acolhe uma série de outros fenômenos de vitimização, nem todos com a mesma visibilidade ou reconhecimento de seu estatuto social e legal (Sani \& Cardoso, 2013). O fenômeno ocorre mais frequentemente entre parceiros íntimos adultos (e.g., violência conjugal), podendo ser direta e/ou indiretamente experimentado por crianças no contexto familiar. A violência doméstica entre pais, também designada por alguns autores (e.g., Bourassa, Lavergne, Damant, Lessard, \& Turcotte, 2006; Jouriles, Rosenfield, McDonald, \& Mueller, 2014; Rossman, Hughes, \& Rosenberg, 1999) como violência interparental é um dos múltiplos fenômenos de vitimização, presente na vida de muitas crianças (Caridade \& Sani, 2016). Embora haja crianças que assistem à agressão perpetrada por um dos seus progenitores sobre o outro, os registos oficiais tendem a destacar apenas a violência conjugal, a não ser que as situações de violência doméstica resultem em letalidade para as crianças (Office for Standards in Education [Ofsted], 2011).

Apesar de ser difícil estimar o número de crianças que vivem em famílias violentas e que assistem direta ou indiretamente à violência doméstica entre os seus progenitores, há evidências científicas de que esse é um fenômeno alarmante com repercussões negativas para o desenvolvimento de crianças e adolescentes (Hamby, Finkelhor, Turner, \& Ormrod, 2010; Patias, Bossi, \& Dell'Aglio, 2014; Jouriles et al., 2014; Sani, 2011a; Sheridan, Glass, Limandri, \& Poulos, 2007; Straus, Gelles \&

*E-mail: anasani@ufp.edu.pt 
Steinmetz, 2006). As consequências negativas da exposição na criança a esse problema familiar podem traduzir-se em alterações fisiológicas, emocionais, cognitivas e comportamentais, que podem serevelar a curto, médio ou longo prazo (Artz et al., 2014; Coutinho \& Sani, 2008; Sani, 2007). Os estudos indicam também que a experiência direta e/ou indireta da violência é um inegável fator de risco para a sua perpetuação em relacionamentos íntimos futuros (Black, Sussman, \& Unger, 2010; Moretti, Bartolo, Craig, Slaney, $\&$ Odgers, 2014; Simon \& Furman, 2010).

A intervenção nessa problemática tem assumido destaque em vários níveis (primário, secundário e terciário) e tem envolvido entidades de diversos quadrantes de atuação social (e.g., a saúde, a educação, a justiça). O presente artigo vem destacar o papel das forças de segurança nas situações de violência doméstica e a posição privilegiada que podem ter para a coleta de informação relevante através dos registros (autos) que produzem e que podem contribuir para uma intervenção mais apropriada e efetiva (Richardson-Foster, Stanley, Miller, \& Thomson, 2012; Rollings \& Taylor, 2008; Stover, Berkman, Desai, \& Marans, 2010). Neste texto pretendemos destacar a natureza inequívoca do risco que correm as crianças expostas à violência doméstica e o papel que as polícias podem ter na sinalização desse risco e, consequentemente, no acionar de mecanismos de proteção, cooperando com outras entidades na promoção de bem-estar e segurança da criança (Richardson-Foster et al., 2012).

Assim, faremos, de início, uma breve contextualização sobre o fenômeno da exposição de crianças à violência doméstica e a sua prevalência. Em seguida, justificaremos a pertinência deste trabalho, discutindo a caracterização que certos estudos fazem sobre a intervenção da polícia junto dessas crianças. $\mathrm{O}$ nosso propósito é lançar as bases conceptuais para possibilitar a apresentação de um estudo quantitativo e qualitativo (misto) baseado na análise de autos policiais referentes a processos por violência doméstica. Entre outros, este trabalho teve por objetivo sinalizar a existência de casos de crianças e jovens expostos à violência doméstica dos progenitores e ilustrar, com base nos conteúdos reportados nos autos, um fenômeno de vitimização infantil com que se confrontam muitos agentes policiais.

\section{CRIANÇAS EXPOSTAS À VIOLÊNCIA DOMÉSTICA:ANÁLISE DA PREVALÊNCIA}

A violência doméstica em Portugal é um fenômeno que marcadamente atinge o sexo feminino (Sistema de Segurança Interna [SIS], 2014). Em uum estudo efetuado em Portugal sobre os custos sociais resultantes da violência exercida contra as mulheres, verificou-se que os espaços sociais mais afetados são o espaço da família e dos amigos (Lisboa, Vicente, Carmo, \& Nóvoa, 2003). Para além da vitimização exercida sobre as mulheres, os autores identificam os filhos como o grupo seguinte de vítimas de violência no espaço familiar. Os resultados obtidos nesse estudo mostraram que cerca de um quinto das mulheres tiveram filhos doentes durante os doze meses anteriores à realização do inquérito $(21,2 \%)$.

Embora não existam em Portugal, como existem em outros países (cf. Hamby et al., 2010), dados empíricos de prevalência que permitam estimar quantas crianças podem estar expostas à violência doméstica entre os pais, alguns dados alertam-nos para a extensão do fenômeno (SSI, 2014). Dados portugueses retirados do relatório anual de segurança interna (RASI) referente ao ano de 2013 apontam que, em $39 \%$ das ocorrências de violência doméstica participadas às autoridades, foi assinalada a presença de crianças (SSI, 2014). Em uma família com filhos, é muito provável que as crianças assistam, em algum momento, à violência doméstica entre os seus cuidadores adultos. De acordo com a literatura, estima-se que entre $60 \%$ e $80 \%$ das crianças em famílias em que ocorrem maus-tratos à mulher testemunham essa violência (Jaffe, Wolfe, \& Wilson, 1990). Além disso, em muitas das situações de violência entre os pais, as crianças são pequenas, o que potencializa um maior risco de impacto em seu ajustamento global. Dados apresentados pelo Observatório do Departamento de Saúde de Rhode Island (EUA), a partir de relatórios da polícia do ano 1996-1998, revelaram que 48\% das crianças que testemunharam incidentes de violência doméstica tinham menos de 6 anos (Gjelsvik, Verhoek-Oftendahl, \& Pearlman, 2003).

A revisão da literatura na área revela que crianças e adolescentes expostos à violência doméstica entre os pais estão em risco elevado de violência direta (e.g., Bourassa et al., 2006; English et al, 2009; Jobe-Shields, Moreland, Hanson, Amstadter, Saunders, \& Kilpatrick, 2015; Sani \& Caprichoso, 2013). Em um estudo com 6000 famílias nos EUA, Abell e Ey (2008) verificaram que mais da metade dos homens que agredia as suas companheiras também agredia frequentemente as suas crianças. Outro dado verificado pelos mesmos autores foi que as mulheres agredidas pelo companheiro tendiam a agredir mais facilmente as suas crianças, comparativamente com mulheres não vítimas de agressão. Em um estudo português com 60 mães, sendo 30 delas vítimas de violência conjugal e 30 não vítimas de violência conjugal, Sani e Cunha (2011) concluíram que as mulheres vítimas de violência utilizavam com maior frequência práticas educativas inadequadas (e.g., punição física) na interação com os seus filhos, classificando-as como adequadas. Em outro estudo, com uma amostra de 1775 famílias residentes na região norte de Portugal, 10,3\% dos participantes admitiram comportamentos abusivos contra as crianças em algum momento, e 21,2\% admitiram cometer atos abusivos, de caráter físico ou psicológico, com 
regularidade (Machado, Gonçalves, \& Matos, 2001),. Como estes, outros estudos revelam que muitas crianças expostas à violência interparental são também alvo direto de algum tipo de violência na família, situando os valores para essa coocorrência entre 30\% a 60\% (Edleson, 2001).

Assim, a literatura na área da vitimização infantil tem vindo demonstrar que são várias as evidências do risco que correm as crianças que vivem em famílias em que existe violência entre os pais. Apesar de serem escassos os números que enunciam a existência do fenômeno, alguns relatórios têm assinalado a sua presença e alertado para as implicações diversas dessa experiência sobre o desenvolvimento infantil.
As consequências decorrem não só da observação direta da violência, mas também da forma como essa situação influencia o funcionamento familiar em termos das práticas educativas, da vinculação e do relacionamento global entre os seus elementos. Uma criança exposta à violência doméstica entre seus cuidadores é uma criança em situação de risco, que deve ser identificada e apoiada, sendo os agentes policiais elementos que estão na linha de frente na resposta social ao problema (Richardson-Foster et al., 2012; Rollings \& Taylor, 2008), podendo e devendo sinalizar esses casos.

\section{A INTERVENÇÃO DA POLÍCIA JUNTO DE CRIANÇAS EXPOSTAS À VIOLÊNCIA DOMÉSTICA}

Nos últimos anos, assistimos em Portugal a mudanças significativas na forma como a polícia tem vindo a caracterizar a sua intervenção junto das vítimas de violência doméstica. Com a implementação em Portugal do Modelo Integrado de Policiamento de Proximidade (MIPP), os agentes policias inseridos nas Equipes de Proximidade e de Apoio à Vítima (EPAV's) obtiveram formação específica nessa problemática social. Essa especialização fundamentase na evidência de que a polícia tem um papel preponderante nesse tipo de situações, seja no apoio, na mediação ou no encaminhamento das vítimas para outras instituições (Machado et al., 2009).

Alguns estudos desenvolvidos junto a agentes policiais concluem que não existem propriamente critérios, diretivas ou procedimentos específicos, previamente estabelecidos, para uma atuação da polícia em situações de violência doméstica entre o casal quando existem crianças expostas à mesma (e.g., Miller, 2016; Stanley, Miller, Foster, \& Thomson, 2010a, 2010b). Se há agentes policias que tendem a abordar a criança, seja com o intuito de obtenção de prova, seja no sentido de avaliar o risco a que está sujeita, há outros que temem fazer essa aproximação com receio de ocasionar dano adicional ou por não saberem o que fazer (Stanley et al., 2010a, 2010b). As situações podem ser delicadas e a própria criança, face à presença dos agentes, pode sentir-se confusa ou amedrontada, receando o que poderá acontecer com ela e com os pais. Segundo Miller (2016), os polícias raramente se comunicam diretamente com as crianças quando respondem aos incidentes de violência doméstica, todavia, quando as abordam, elas experienciam a interação como positiva. De acordo com o autor, boas práticas da polícia perante crianças expostas à violência doméstica podem incluir acalmar a criança, restaurar a sua segurança, avaliar as suas necessidades e colaborar com outras entidades (Miller, 2016). Assim, considera-se que o conhecimento e o treino de competências dos agentes policiais para a intervenção junto a essas crianças deve integrar igualmente a sua formação especializada (Miller, 2016; Richardson-Foster et al., 2012).

Importa, ainda, frisar a contribuição dos agentes para o andamento dos processos, especialmente através da realização dos autos de notícia ou de denúncia. Os autos policiais permitem a outros profissionais (e.g., Magistrados) uma compreensão dos fatos mais exaustiva e rigorosa, podendo prestar uma excelente contribuição em diversas as fases do processo criminal. Refira-se, a título de exemplo, que o Código Penal Português prevê, no seu artigo $152^{\circ}$, referente à Violência Doméstica, a possibilidade de agravação da pena ao agressor, em um ano no seu limite mínimo, caso se comprove que a violência foi perpetrada "contra menor, na presença de menor, no domicílio comum ou no domicílio da vítima" (Lei 59/2007). Assim, considerando que informação relevante sobre as crianças pode constar dos autos, pode a polícia proporcionar uma melhor qualidade da investigação e mais provas, bem como conferir autoridade e segurança ao processo e ao trabalho desempenhado por outras associações de apoio à vítima (Cross, Finkelhor, \& Ormrod, 2005). Por norma, a Polícia de Segurança Pública (PSP) portuguesa tem de, paralelamente ao registro da queixa por violência doméstica, remeter a outras entidades públicas, designadamente às Comissões de Proteção de Crianças e Jovens (CPCJ's), todas as situações em que seja assinalada a presença de crianças em situações de risco.

Nesse sentido, consideramos pertinente extrair de um estudo mais amplo que realizamos e cujo método incluiu a análise de autos policiais, dados que nos pudessem esclarecer sobre o fenômeno, por vezes invisível, da exposição de crianças à violência doméstica de seus cuidadores e caracterizá-lo, baseando-nos nas descrições efetuadas nos autos. 


\section{MÉTODO}

O estudo exploratório que passamos a descrever apresenta uma componente quantitativa e outra qualitativa, tendopor objetivo a análise e a interpretação de dados recolhidos através dos autos de notícia (quando a polícia é chamada ao local) e de denúncia (quando há uma comunicação na esquadra) de situações de violência doméstica participadas a uma esquadra de PSP do Porto (Portugal), no ano de 2010. Procurou-se, primeiramente, realizar uma caracterização das situações a partir do total dos registros disponíveis relativos a autos por violência doméstica. Consideraram-se especificamente a presença ou não de filhos, o contexto das agressões, as características sociodemográficas da vítima e do ofensor e tipologia mais frequente de violência. Posteriormente, centrados apenas nos autos referentes à violência doméstica entre parceiros íntimos, realizamos uma análise pormenorizada dessas situações envolvendo crianças, tendo por base as «descrições narrativas dos fatos».

A amostra para este estudo foi composta por 167 autos policiais relacionados com o crime de violência doméstica, cuja consulta foi previamente autorizada pela Direção Nacional da PSP em Lisboa. O parecer positivo foi transmitido ao Comando Metropolitano do Porto (Portugal), o qual autorizou o início da coleta dos dados sob a supervisão do Comandante de uma Esquadra da cidade do Porto. Os dados foram acessados em papel e consultados na própria esquadra, sendo estritamente garantida a confidencialidade e anonimato das pessoas visadas.

Posteriormente, dos 167 autos, foram selecionados para consulta das descrições dos fatos um total de 141, os quais diziam respeito especificamente a casos de violência doméstica entre parceiros íntimos. Tais casos, no que se refere à relação do ofensor com a vítima caracterizam-se da seguinte forma: companheiro(a) $(n=49)$; ex-companheiro(a) ( $n=37)$; cônjuge ( $n=42)$ e ex-cônjuge $(n=13)$.

O tratamento de informação passou por duas tipologias: a criação de uma matriz quantitativa em Excel, baseada no modelo padrão dos autos para situações de violência doméstica, com o objetivo de registrar o conjunto de informações demográficas e caracterizadoras dos casos em análise; e o desenvolvimento de uma matriz conceptual que emergiu da análise de conteúdo das narrativas descritas nos autos e que originaram a constituição de categorias (Bardin, 2009). A análise categorial permitiu a emergência de seis categorias (tipologias da violência; dinâmicas da violência; fatores de risco; presença de crianças; atuação policial; e vítima e denúncia), as quais deram origem a diversas subcategorias. Os dados quantitativos e qualitativos a seguir apresentados representam apenas os que se referem à categoria emergente Presença de Crianças.

\section{RESULTADOS}

Relativamente aos dados quantitativos, observou-se que $55,1 \%$ da amostra não tinha filhos e que $44,9 \%$ tinha pelo menos uma criança, especificamente $22, .2 \%$ tinha um filho; $13,8 \%$, dois; e $6 \%$, três crianças, havendo cinco casos com quatro ou mais crianças no núcleo. Quanto à presença de crianças no contexto da agressão, a mesma está referenciada em 49 dos 167 autos analisados $(29,3 \%)$.

Os dados revelam que a violência a que estavam expostas essas crianças era frequentemente perpetrada sobre vítima de sexo feminino (83\%). Quanto às faixas etárias, as vítimas pertenciam majoritariamente ao grupo entre os 31 e os 35 anos (15,5\%), seguido do grupo dos 26 a 30 anos (14,4\%). Quando aos agressores, a maioria é do sexo masculino $(80 \%)$, encontrando-se muito frequentemente no grupo etário entre os 36 e os 40 anos (16,7\%), seguido do grupo entre os 41 e os 45 anos (16,2\%). Nas habilitações literárias reveladas, ambos os grupos apresentavam o $1^{\circ}$ ciclo de ensino como o nível de estudos mais frequente $(26,9 \%$ nos ofensores e 23,4\% nas vítimas).

Em relação ao tipo de violência, a psicológica foi a mais reportada $(n=130)$, seguida da violência física $(n=110)$. Relativamente à violência psicológica, encontramos assinalados nos autos, por exemplo, comportamentos de ameaças contra a integridade física, ameaças de morte sem ou com uso de armas, injúrias, humilhação, isolamento da vítima, chantagem emocional, pressão para que a vítima cometa suicídio, entre outros. Deve-se, ainda, relatar a existência de comportamentos de assédio persistente (stalking; e.g., perseguição da vítima na sua residência, na via pública ou no seu local de trabalho, contatos telefônicos ameaçadores, ameaças através das redes sociais na internet). No que se refere à violência física, surgem nos autos descrições de comportamentos como empurrar a vítima, agarrar e arrastar a vítima, projetar violentamente a vítima, recurso a pontapés, murros, cabeçadas e mordeduras, agressões com recursos a objetos ocasionais como pedras ou canecas de vidro. A violência econômica (e.g., extração do dinheiro da vítima) e a violência sexual (e.g., força relações sexuais com a companheira) surgem também registadas, embora de modo muito menos frequente, sendo comumente menos perceptíveis pelas crianças.

Quando analisamos o conteúdo dos autos policiais, destacaram-se vários aspectos quanto ao envolvimento ou impacto direto e/ou indireto de crianças nas situações de violência doméstica. Nesse sentido, constituiu-se uma categoria que denominamos de Presença de Crianças, na 
qual se incluem três subcategorias: Exposição à Violência Doméstica; Maus-Tratos Físicos e/ou Psicológicos, Instrumentalização dos Filhos por parte dos Progenitores.

Relativamente à primeira categoria emergente, Exposição à Violência Doméstica, a análise aos autos revela a existência de vitimização indireta de crianças no decurso ou no âmbito de episódios de violência doméstica: Auto 4 -“... havia sido agredida com socos e pontapés em todo o corpo, pelo suspeito, que é seu companheiro, na presença das suas filhas menores"; Auto 42 - "De referir que essas agressões, tanto verbais como as físicas foram efetuadas, na presença de três filhos menores, sendo estes, um bebê com 23 dias de idade, que ainda não tem nome e é filho de ambos, o L., com 2 anos de idade, filho de M. apenas, e o filho de J., com o nome de JC, com 13 anos de idade ...”; Auto 93 -“... fatos foram presenciados por uma criança (menor de idade) que posteriormente vim a verificar que se tratava do filho de ambos, de sete anos de idade..."; Auto 104 - verificou que A. devidamente identificada como suspeita, se encontrava alcoolizada, tendo esta começado a injuriar e a agredir o $\mathrm{M}$. na presença dos menores...”; Auto 155 - “... quando das agressões, se encontravam em casa três filhos menores a dormir, bem como outro filho maior de idade de nome M., que assistiu a tudo...".

Em alguns autos, é feita referência à existência de situações de Maus-Tratos Físicos elou Psicológicos de que foram vítimas diretas algumas das crianças dos núcleos familiares dos autos: Auto 5 -“...o mesmo deu dois estalos na cara da filha de ambos. Tudo se passou quando estava a ter uma discussão normal com a sua esposa, tendo a sua filha se intrometido no meio da discussão e como estava um pouco nervoso deu-lhe dois estalos na face, tendo-lhe provocado um pequeno ferimento no interior da boca...”; Auto 77 - “... tendo já sido agredida, bem como a filha menor de ambos, de nome T. (...), por várias vezes, contudo nunca foram participadas à autoridade...”; Auto 119 - “...existe uma filha (E), com 15 anos de idade (...) A sua filha também foi agredida com uma chapada no rosto, mas não a levou consigo ao hospital por achar que não seria necessário e para poupar a filha às consequentes situações desagradáveis...".

Em apenas três autos foram destacados maus tratos psicológicos: Auto 20 - "Verifiquei que se encontrava o lesado, menor com 6 anos de idade junto ao vigilante da empresa ... o qual tentava acalmar o menor que se apresentava nervoso e a chorar "; Auto 23 - "De salientar que, segundo a vítima, o suspeito está sempre a tratar mal os seus filhos, sempre que a sua filha $T$. chega a casa do emprego ele diz que ela não anda a trabalhar mas sim na prostituição ... está sempre a chamar de burro e gordo ao $\mathrm{H}$. ..."; Auto 89 - "Quando a filha faz algum comentário ... este grita-lhe para ir para o quarto, dizendo-lhe: porque tens de estar sempre onde estamos a discutir; a tua mãe já te fez a cabeça? Cala-te! ... A filha pergunta várias vezes ao pai se tem culpa das discussões ao que ele lhe responde que só tem culpa porque já tem a cabeça feita pela mãe".

A análise de conteúdo dos autos permitiu, ainda, extrair outra subcategoria referente às crianças e que foi designada de Instrumentalização dos Filhos. As situações aqui descritas remetem sobretudo para outros aspectos de vitimização a criança, por vezes, já após a separação e divórcio dos intervenientes. Assim, surgem refletidas nos autos situações em que as crianças acabam por ser objeto de injúrias verbais, ameaças à integridade física e psicológica e chantagem emocional, quando, no contexto da situação, estas são usadas enquanto meio para que os progenitores perpetuem as agressões: Auto 37 - “...desta discussão resultou que ambos decidiram cessar o relacionamento naquele momento, pelo que $\mathrm{B}$. lhe retirou a menor dos braços refugiando-se com a mesma no interior da residência, não lhe permitindo o acesso..."; Auto 48 - “ ... conversou com a suspeita e ela disse-lhe, em tom de chantagem que, caso ele não lhe dê dinheiro a quantia de 225 euros mensais não o deixava mais ver os filhos ..."; Auto 82 - "H., munido de um ferro com cerca de um metro de comprimento, exigiu a $\mathrm{M}$. que lhe indicasse o paradeiro de P., uma vez que lhe queria retirar os filhos menores que, segundo o qual, também eram dele ..."; Auto 86 - “... foi acordado entre ambos que a vítima deixaria, quando tal fosse combinado, o suspeito de ver o seu filho (...) a vítima foi com o seu filho à estação do metro da Trindade, onde compareceu o suspeito já bastante alterado. Ainda ali começou a falar em voz alta fazendo alarido. Então a vítima abandonou o local com o menor, para que o suspeito a deixasse em paz. Tal não aconteceu e este seguiu-a fazendo sempre escândalo pela rua, ao mesmo tempo que falava em voz alta, dizendo que queria levar com ele o filho...".

\section{DISCUSSÃO}

Um dos aspectos salientados pela análise quantitativa dos dados é que, em $45 \%$ dos casos participados por violência doméstica, os intervenientes têm um ou mais filhos. Esse dado genérico alerta-nos, desde já, para o risco acrescido de crianças em famílias em que existe violência entre os pais também serem vítimas de agressões, tal como sustentado por alguns estudos (Hamby et al., 2010; Jaffe et al.,1990). A visibilidade dessas crianças, bem como do risco a que estão expostas na família, nem sempre é priorizada e, em muitos dos autos da polícia, a narrativa dos fatos foca a violência do casal. A realidade é que há evidências do fenômeno e a análise que realizamos dos autos policiais constituiu uma oportunidade para sublinhar o importante papel que a polícia poderá ter na sinalização dessas crianças em situação de risco (Ofsted, 2011). 
Os dados obtidos apontam para $29 \%$ das crianças estarem presentes quando da ocorrência da situação denunciada, uma percentagem que carece de alguma margem de imprecisão, se consideramos que, muitas vezes, os progenitores ou figuras parentais da criança negam a sua presença ou se atendermos à hipótese de os agentes policias não terem tido indicação ou observado o assistir dos episódios pelas crianças da casa. Os dados oficiais do RASI de 2013 anunciam uma percentagem maior, em torno dos $39 \%$ (SSI, 2014), a qual tem sido congruente com outros relatórios do SSI em Portugal. A possibilidade das cifras negras para esse fenômeno já é de todo conhecida, mas a diversidade de percentagens que possam ser encontradas, embora díspares, é suficiente para nos alertar para a existência preocupante desse problema.

Em uma análise discursiva das narrativas descritas nos autos, é de notar, ainda, como a referência às crianças é feita considerando-as mais no papel de testemunhas (e.g., “... foram presenciados..."; “...na presença de..."; "assistiu a tudo..."; Richardson-Foster et al., 2012) do que de vítimas, mesmo que indiretas, das situações de violência doméstica, condição que a lei portuguesa prevê que seja verificada. De algum modo, reflete-se o que a literatura nessa matéria vem constatando sobre o foco colocado nas relações violentas entre adultos, não tendo as crianças uma "voz" nos processos oficiais (Ofsted, 2011). Todavia, alguns dos autos mostram expressamente como a violência se estende diretamente às crianças, que chegam elas próprias a ser alvo da violência dos pais (e.g., "...tendo a sua filha se intrometido no meio da discussão... deu-lhe dois estalos na face..."; “... tendo já sido agredida, bem como a filha menor ..."; "A sua filha também foi agredida com uma chapada no rosto..."). A coexistência da violência sobre o cônjuge e sobre a criança tem sido constatada por vários estudos (Bourassa et al., 2006; Edleson, 2001; English et al., 2009; Jobe-Shields et al., 2015; Machado et al. 2001; Sani \& Caprichoso, 2013) que reforçam o risco cumulativo da vitimização múltipla (Caridade \& Sani, 2016) para o ajustamento da criança, sobretudo em fases precoces do seu desenvolvimento (Gjelsvik et al., 2003).

A violência doméstica a que assistem essas crianças tem como protagonistas os seus cuidadores e ocorre, sobretudo, no seu contexto de acolhimento e desenvolvimento, tendo características de agressão física e psicológica, direta e indiretamente experienciadas, capazes de alterar negativamente seu percurso desenvolvimental em vários níveis (Coutinho \& Sani, 2008; Patias et al., 2014; Sani, 2007). As experiências de abuso na família são um fator de risco considerado em diversas investigações (Buzawa \& Buzawa, 2002; Sheridan et al., 2007; Straus et al., 2006). Essa experiência constitui um forte preditor para a violência física e psicológica contra as crianças, muitas vezes, aceita enquanto prática educativa (Machado et al., 2001; Sani \& Cunha, 2011).
Os resultados mostraram, ainda, como as crianças são usadas para o controle ou exercício de violência e em acordos entre o casal que privilegiam a relação conjugal (e.g., "... foi acordado entre ambos...": “...ambos decidiram...") e ignoram as necessidades e direitos da criança. Algumas das descrições nos autos revelaram como as crianças são, por vezes, alvo de instrumentalização pelos pais (e.g., " “... lhe retirou a menor dos braços..."; “...não o deixava mais ver os filhos"; "... que the queria retirar os filhos menores que, segundo o qual, também eram dele ...”; “... este seguiu-a... dizendo que queria levar com ele o filho...”). A existência dessas situações contradiz o que vem consignado nos diplomas legais quanto a obrigação dos responsáveis pela criança de garantirem sua proteção, salvaguardarem seus direitos e satisfazerem suas necessidades (e.g., na saúde, educação, segurança, sustento económico; Gonçalves \& Sani, 2015). Essa instrumentalização dos filhos em casos de violência entre os pais evidencia de per si um indicador do risco que enfrentam essas crianças expostas à violência entre os pais (Jaffe et al.,1990).

Os agentes policiais identificam as crianças nas situações de violência doméstica entre os pais, mas não salientam quaisquer consequências ou fatores que enunciem o risco a que estão expostas. Lidar com situações de crianças expostas à violência doméstica exige conhecimento da problemática e treino de competências para a avaliação desses casos, o que os próprios agentes poderão ter no âmbito da formação especializada. Além dos sinais e sintomas mais comuns (e.g., agressividade, medos, tristeza), há uma série de outros mais sutis que se deve saber avaliar (Edleson et al., 2007) ou não minimizar, sob pena de não se prevenir o risco para a criança. $\mathrm{O}$ fato de uma criança não apresentar ferimentos físicos visíveis não é suficiente para declarar a inexistência de risco, porque este existe desde o momento em que o menor está exposto à violência no seu espaço doméstico.

Partilhamos da opinião de que a polícia, como primeira entidade de contato com as situações de violência doméstica, poderá ter um papel vital na sinalização de casos de crianças em risco (Rollings \& Taylor, 2008). Na verdade, os polícias são para muitas destas crianças os primeiros profissionais com quem elas têm contato quando a violência ocorre dentro de casa (Överlien \& Aas, 2015). Isso impõe que os agentes de polícia reconheçam e discriminem os diversos níveis de necessidades dessas crianças, sendo que a informação e o treino sobre o risco da exposição da criança à violência doméstica poderá contribuir para promover as competências e a confiança dos mesmos na abordagem da criança nesses contextos (Richardson-Foster et al., 2012). Assim, o treino específico desses profissionais sobre o tema da violência doméstica pode permitir a construção de planos de segurança e o manusear de instrumentos e materiais (cf. VIGOR_The Victim Inventory of Goals, Options, \& Risks) que possibilitem uma intervenção mais eficaz com as crianças (Miller, 2016). Alguns projetos (e.g., Violence Intervention 
Programme for Children and Families; Domestic Violence Home Visit Intervention) que incluem um foco particular no problema da exposição da criança à violência doméstica e em suas necessidades constituem referências interessantes para a elaboração de propostas interventivas junto a agentes policiais (cf. Osofsky, 1998).

\section{CONCLUSÃO}

A violência doméstica é um problema de responsabilidade social, que viola a igualdade e os direitos humanos, devendo ser combatida por todos os agentes sociais. Os registros criminais oficiais em Portugal destacam a violência doméstica como o crime mais denunciado às forças de segurança, ao qual se associam seguramente um número irreconhecível de cifras negras. Se a essa problemática associarmos a exposição de inúmeras crianças e adolescentes, despertamos para o risco inestimável que correm muitas delas de ver o seu ajustamento global afetado.

Os dados dos autos policiais são uma peça probatória importante para compreendermos que, no âmbito da violência doméstica, os filhos são frequentemente um grupo de grande vulnerabilidade no espaço familiar. Os resultados deste estudo realizado corroboram estudos anteriores quanto à evidência do fenômeno e reforçam o interesse particular para a compreensão de realidades emergentes na vitimização (Sani, 2011b). Reafirmamos a importância do treino especializado dos agentes policiais, na medida em que isso proporcionaria uma resposta mais eficaz e eficiente a um fenômeno social cada vez mais visível, com repercussões negativas para o desenvolvimento da criança. $O$ treino desses profissionais para a sinalização do risco, a capacitação para o diagnóstico de necessidades da família e da criança e a cooperação estratégica entre as diversas entidades permitirá um foco assertivo do sistema de justiça na melhor forma de garantir a proteção da criança e um futuro que pode começar pela quebra do ciclo de violência.

\section{REFERÊNCIAS}

Abell, S., \& Ey, J. (2008). Domestic violence: Its impact on children. Clinical Pediatrics, 47(4), 413-415. http://dx.doi. org/10.1177/0009922807303550

Artz, S., Jackson, M. A., Rossiter, K. R., Nijdam-Jones, A. Géczy, I., \& Porteous, S. (2014). A comprehensive review of the literature on the impact of exposure to intimate partner violence for children and youth. International Journal of Child, Youth and Family Studies 5(4), 493-587. http://citeseerx.ist.psu. edu/viewdoc/download?doi=10.1.1.846.9277\&rep=rep1\&t ype $=$ pdf

Bardin, L. (2009). Análise de Conteúdo. Coimbra: Edições 70.

Black, D. S., Sussman,S., \& Unger, J. B. (2010). A further look at the intergenerational transmission of violence: Witnessing interparental violence in emerging adulthood. Journal of Interpersonal Violence, 25(6), 10221042.

Bourassa, C., Lavergne, C., Damant, D., Lessard, G., \& Turcotte, P. (2006). Awareness and detection of the co-occurrence of interparental violence and child abuse: Child welfare worker's perspective. Children and Youth Services Review, 28, 1312-1328.

Buzawa, E. S., \& Buzawa, C. G. (2002). Domestic violence: The criminal justice response. Thousand Oaks: SAGE Publications.

Caridade, S., \& Sani, A. (2016). Vitimação múltipla infantil e juvenil. In A. Sani \& S. Caridade (Coord.), Práticas de intervenção na violência e no crime (pp. 3-18). Lisboa: Pactor.

Coutinho, M. J., \& Sani, A. I. (2008). Evidência empírica na abordagem sobre as consequências da exposição à violência interparental. Revista da Faculdade de Ciências Humanas e Sociais, 5, 284-293.

Cross, T. P., Finkelhor, D., \& Ormrod, R. (2005). Police involvement in child protective services investigations: Literature review and secondary data analysis. Child Maltreatment, 10, 224-244. http://dx.doi.org/10.1177/1077559505274506

Eckstein, J. J. (2011). Reasons for staying in intimately violent relationships: Comparisons of men and women and messages communicated to self and others. Journal of Family Violence, 26, 21-30. http://dx.doi.org/10.1007/s10896-010-9338-0
Edleson, J. L. (2001). Studying the co-occurrence of child maltreatment and domestic violence in families. In S. A. Graham-Bermann, \& J. Edleson (Eds.), Domestic violence in the lives of children: The future of research, intervention and social policy (pp. 91-110). Washington: American Psychological Association.

Edleson, J. L., Ellerton, A. L. Seagren, E. A., Kirchberg, S. L., Schmidt, S. O., \& Ambrose, A. T. (2007). Assessing child exposure to adult domestic violence. Children and Youth Services Review, 29, 961-971. http://dx.doi.org/10.1016/j. childyouth.2006.12.009

English, J. D., Graham, J. C., Newton, R. R., Lewis, T. L., Thompson, R., Kotch, J. B., \& Weisbart, C. (2009). At-risk and maltreated children exposed to intimate partner aggression/ violence - What the conflict looks like and its relationship to child outcomes. Child Maltreatment, 14, 157-171.

Gjelsvik, A., Verhoek-Oftendahl, W., \& Pearlman, D. N. (2003). Domestic violence incidents with children witnesses: Findings from Rhode Island surveillance data. Women's Health Issues, 13, 68-72. http://dx.doi.org/10.1016/S1049-3867(02)00197-4

Gonçalves, M., \& Sani, A. (2015). A participação da criança na justiça: estudo com crianças expostas à violência doméstica. Revista Psicologia da Criança e do Adolescente, 6(1), 157169. http://revistas.lis.ulusiada.pt/index.php/rpca/article/ view/1978/2095

Hamby, S., Finkelhor, D., Turner, H., \& Ormrod, R. (2010). The overlap of witnessing partner violence with child maltreatment and other victimizations in a nationally representative survey of youth. Child Abuse and Neglect, 34, 734-741.

Hardesty, J. L., \& Ganong, L. H. (2006). How women make custody decisions and manage co-parenting with abusive former husbands. Journal of Social and Personal Relationships, 23(4), 543-563. http://dx.doi.org/10.1177/0265407506065983

Jaffe, P., Wolfe, D., \& Wilson, S. (1990). Children of battered woman. USA: Sage Publications.

Jobe-Shields, L., Moreland, A. D., Hanson, R., Amstadter, A. Saunders, B. E., \& Kilpatrick, D. G. (2015). Co-occurrence of 
witnessed parental violence and child physical abuse from a national sample of adolescents. Journal of Child \& Adolescent Trauma. https://doi.org/10.1007/s40653-015-0057-9

Jouriles, E., Rosenfield, D., McDonald, R., \& Mueller, V. (2014). Child involvement in interparental conflict and child adjustment problems: A longitudinal study of violent families. Journal of Abnormal Child Psychology, 42, 693-704.

Lei 59/2007 de 4 de setembro. Diário da Republica, $1^{\circ}$ serie, $\mathrm{n}^{\circ} 170$, 4 de setembro de 2007. Vigésima terceira alteração ao Código Penal aprovado pelo D.L. 400/82 de 23 de setembro.

Lisboa, M., Vicente, L., Carmo, I., \& Nóvoa, A. (2003). Os custos sociais e económicos da violência contra as mulheres. Lisboa: CIDM.

Machado, C., Gonçalves, M., \& Matos, M. (2001). Práticas educativas parentais e violência: um estudo na região norte. Atas dos Ateliers do $V^{o}$ Congresso Português de Sociologia, 37-43. http://www.aps.pt/cms/docs prv/docs/ DPR4628ce2013904 1.pdf.

Machado, C., Matos, M., Saavedra, R., Cruz, O., Antunes, C., Pereira, M., ... Capitão, L. (2009). Crenças e atitudes dos profissionais face à violência conjugal: Estudos com profissionais de saúde, polícias e professores. Ata Médica Portuguesa, 22(6), 735-742.

Miller, M. (2016). How police respond to family violence involving children. Domestic Violence Report, Civic Research Institute, 21(2), 23-25. https://www.civicresearchinstitute.com/online/ article abstract.php?pid=18\&iid $=1145 \&$ aid $=7500$

Moretti, M. M., Bartolo, T., Craig, S., Slaney, K., \& Odgers, C. (2014). Gender and the transmission of risk: A prospective study of adolescent girls exposed to maternal versus paternal interparental violence. Journal of Research on Adolescence, 24(1), 80-92.

Office for Standards in Education. (2011). The voice of the child: Learning lessons from serious case reviews - A thematic report of Ofsted's evaluation of serious case reviews. Manchester: Ofsted.

Osofsky, J. D. (1998). Children in a violent society. New York: Guilford Publications.

Överlien, C., \& Aas, G. (2015). The police patrols and children experiencing domestic violence. Police Practice and Research, 17(5), 434-447. http://dx.doi.org/10.1080/15614263.2015.10 86879

Patias, N. D., Bossi, T. J., \& Dell'Aglio D. D. (2014). Repercussões da exposição à violência conjugal nas características emocionais dos filhos: Revisão sistemática da literatura. Temas em Psicologia, 22(4), 901-915.

Richardson-Foster, H., Stanley, N., Miller, P., \& Thomson, G. (2012). Police intervention in domestic violence incidents where children are present: Police and children's perspectives. Policing and Society, 22(2), 220-234. http://dx.doi.org/10.108 0/10439463.2011.636815

Rossman, B. B. R., Hughes, H. M., \& Rosenberg, M. S. (1999). Children and interparental violence: The impact of exposure. Philadelphia, PA: Taylor \& Francis.
Rollings, K., \& Taylor, N. (2008). Measuring police performance in domestic and family violence. Trends \& Issues in Crime and Criminal Justice, 367. Recuperado de http://www.aic.gov.au/ media library/publications/tandi pdf/tandi367.pdf

Sani, A. I. (2007). Las consecuencias de la violencia interparental en la infancia. In R. Arce, F. Fariña, E. Alfaro, C. Civera, \& F. Tortosa (Eds.), Psicología jurídica. Violencia y victimas (pp. 13-21). Valencia: Sociedad Española de Psicología y Ley.

Sani, A. I. (2011a). Crianças vítimas de violência: Representações e impacto do fenómeno. Porto: Edições UFP.

Sani, A. I. (2011b). Temas de Vitimologia: Realidades emergentes e respostas sociais. Coimbra: Editora Almedina.

Sani, A., \& Caprichoso, D. (2013). Crianças em situação de risco por exposição à violência doméstica. In M. Calheiros \& M. Garrido (Eds.), Crianças em risco e perigo: Contextos, investigação e intervenção (Vol. 3., pp.191-207). Lisboa: Edições Sílabo.

Sani, A. I., \& Cardoso, D. (2013). A Exposição da criança à violência interparental: Uma violência que não é crime. Revista Julgar Online, 4, 1-10.

Sani, A. I., \& Cunha, D. (2011). As práticas educativas parentais em mulheres vítimas e não vítimas de violência conjugal. Psicologia: Teoria e Pesquisa, 27(4), 429-437. http://dx.doi. org/10.1590/S0102-37722011000400006

Simon, V. A., \& Furman, W. (2010). Interparental conflict and adolescents' romantic relationship conflict. Journal of Research on Adolescence, 20(1), 188209. http://dx.doi.org/10.1111/ j.1532-7795.2009.00635.x

Sistema de Segurança Interna. (2014). Relatório Anual de Segurança Interna (RASI) 2013. Lisboa: Direção Geral da Administração Interna. Recuperado de http://www.portugal. gov.pt/media/1379710/RASI\%202013.PDF

Sheridan, D. J., Glass, N., Limandri, B. J., \& Poulos, C. A. (2007). Prediction of interpersonal violence: An introduction. In J. C. Campbell (Orgs.), Assessing dangerousness: Violence by batterers and child abusers (pp. 1-23). New York: Springer Publishing Company.

Stanley, N., Miller, P., Foster, H. R., \& Thomson, G. (2010a). Children and families experiencing domestic violence: Police and children's social services' responses. London: National Society for the Prevention of Cruelty to Children. Recuperado de https://library.nspcc.org.uk/HeritageScripts/Hapi.dll/ search2? searchTerm $0=\mathrm{C} 3179$

Stanley, N., Miller, P., Foster, H. R., \& Thomson, G. (2010b). Children's experiences of domestic violence: Developing an integrated response from police and child protection services. Journal of Interpersonal Violence, $X X(X), 1-20$.

Stover, C., Berkman, M., Desai, R., \& Marans, S. (2010). The efficacy of a police-advocacy intervention for victims of domestic violence: 12 months follow-up data. Violence Against Women, 16(4), 410-425. http://dx.doi.org/10.1177/1077801210364046

Straus, M. A., Gelles, R. J., \& Steinmetz, , S. K. (2006). Behind closed doors: Violence in the American family. New York: Transaction Publishers. 